\title{
Optical, Scintillation and Dosimeter Properties of MgO Translucent Ceramic Doped with $\mathrm{Cr}^{3+}$
}

\author{
Takumi Kato, Go Okada and Takayuki Yanagida \\ Nara Institute of Science and Technology (NAIST) \\ 8916-5, Takayama-cho, ikoma-shi, Nara 630-0192, Japan \\ Phone:+81-743-72-6144 Email: kato.takumi.ki5@ms.nasit.jp
}

\begin{abstract}
We have investigated the photoluminescence (PL), scintillation and thermally-stimulated luminescence (TSL) dosimeter properties of $\mathrm{MgO}$ translucent ceramic doped with $\mathrm{Cr}^{3+}$ ion $(0.001$, 0.01 and $0.1 \%$ ). The ceramic samples were synthesized by a Spark Plasma Sintering (SPS) technique. The broad and sharp emission peaks appeared around $600-850 \mathrm{~nm}$ in all the samples. The PL decay time constants of all the samples were a few ms which were on the typical order of $\mathrm{Cr}^{3+}$ doped phosphors. As with the PL, the peak resulted from $\mathrm{Cr}^{3+}$ ion was detected in the scintillation spectra. The TSL glow curves showed the main peak around $140{ }^{\circ} \mathrm{C}$. The TSL response was confirmed to be linear to the irradiation dose over the dose range from 0.1 to $1000 \mathrm{mGy}$.
\end{abstract}

Keywords: translucent ceramic, MgO, Cr, scintillator, dosimeter, TSL 


\section{Introduction}

Accurate measurements of radiation dose, energy and spatial distribution have been demanded, for example, in medical [1], security [2] and also for personal dose monitoring [3-5] applications. Required dosimeter properties depend on applications, but typically suitable sensitivity, dose linearity, energy response and low fading are considered. In addition, if one is to measure a radiation dose absorbed in human body, it is desirable that the effective atomic number $\left(Z_{\text {eff }}\right)$ of the dosimeter material, in the view point of bioequivalence, is close to that of the soft tissue $\left(Z_{\text {eff }}=7.13\right)$. With such a tissue equivalent detector, no mathematical calibration for energy dependence is required ideally. Therefore, for such dosimeter applications, it is preferred for the detector materials to consist of light elements. Dosimeters using an inorganic phosphor are mainly classified in to three types: thermally stimulated luminescence (TSL), optically stimulated luminescence (OSL) and radiophotoluminescence (RPL) dosimeters. Examples of these dosimeter materials used in practice are: $\mathrm{Ti}$ and $\mathrm{Mg}$ doped LiF ceramics [3], C-doped $\mathrm{Al}_{2} \mathrm{O}_{3}$ crystalline powder [4] and Ag-doped phosphate glass [5], respectively.

Magnesium oxide $(\mathrm{MgO})$ is a wide band-gap insulator $\left(E_{\mathrm{g}}=7.8 \mathrm{eV}\right)$ with a rock-salt crystal structure (fcc) under ambient pressure, and the Mg ions occupy the octahedral sites within the anion close-packed structure $[6,7]$. In the 1970 s, undoped $\mathrm{MgO}$ was found to show dosimeter properties. When it was irradiated by X-ray, $\gamma$-ray and UV, two TSL glow peaks were found around $90-100$ and $140{ }^{\circ} \mathrm{C}$ [8-10]. Moreover, it was reported that the emission wavelength appeared at 400 and $710 \mathrm{~nm}$, and the latter is due to contamination of $\mathrm{Cr}$ ion. On the other hand, similar studies have been performed for $\mathrm{MgO}$ powder doped with isoelectronic impurities and transition metal ions. It was revealed that $\mathrm{Cr}^{3+}, \mathrm{Mn}^{2+}$ and $\mathrm{Ni}^{2+}$ act as emission centers while $\mathrm{Fe}^{3+}, \mathrm{Co}^{2+}$ and $\mathrm{Cu}^{2+}$ act as quenchers in $\gamma$-ray induced TSL $[11,12]$.

In addition to the dosimeter properties, the luminescence of undoped $\mathrm{MgO}$ has been studied in many material forms including powders, films, bulk single crystals and ceramics [13-22]. In $\mathrm{MgO}$ crystals, it has been demonstrated that there are two primary oxygen vacancies, namely $\mathrm{F}^{+}$and $\mathrm{F}$ color centers, which capture one and two electrons, respectively. Although absorption bands of the $\mathrm{F}^{+}$and $\mathrm{F}$ color centers are almost the same energy, $\sim 5 \mathrm{eV}(\sim 250 \mathrm{~nm})$, they show different photoluminescence (PL) emission bands with the peaks at $\sim 2.3 \mathrm{eV}(\sim 500 \mathrm{~nm})$ and $\sim 3.2 \mathrm{eV}(\sim 400 \mathrm{~nm})$, respectively [18]. In recent years, with advancement of ceramic fabrication techniques, $\mathrm{MgO}$ transparent ceramic was developed [23-27]. It shows phosphorescence (or called long afterglow or persistent luminescence) emission at the wavelength of $390 \mathrm{~nm}$ due to the $\mathrm{F}^{+}$center acting as a luminescent center [27]. The phosphorescence, in other words, is a form of TSL at room temperature; therefore, the $\mathrm{MgO}$ transparent ceramic is potentially applicable for TSL dosimeter if the TSL peak temperature can be somehow increased in order to store the dose signal for a long term without fading.

In this study, we have synthesized a $\mathrm{MgO}$ translucent ceramic doped with $\mathrm{Cr}^{3+}$ ion $(0.001,0.01$ and $0.1 \%$ ) by spark plasma sintering (SPS) and studied the dosimeter properties against X-rays. Since the contamination of $\mathrm{Cr}$ in $\mathrm{MgO}$ raw powder is unavoidable by purification techniques nowadays, 
investigations of influences of $\mathrm{Cr}$ doping in $\mathrm{MgO}$ are important. Further, we have characterized the optical and scintillation properties. Recently, it was pointed out that scintillation and dosimeter are complementarily related in some material systems $[28,29]$ so investigations of both the dosimeter and scintillation properties are important to understand the luminescence phenomena induced by radiations. In general, SPS is performed in a highly reductive atmosphere; therefore, oxygen vacancies are effectively created, and the dosimeter properties expected to be enhanced.

\section{Experiment}

$\mathrm{MgO}$ transparent ceramic samples were synthesized by an SPS method using Sinter Land LabX-100. Here, a reagent grade of $\mathrm{MgO}(99.99 \%)$ and $\mathrm{Cr}_{2} \mathrm{O}_{3}(99.99 \%)$ powder was homogeneously mixed. The total mass of the mixture was $0.5 \mathrm{~g}$. The mixture was then loaded in a graphite die and sandwiched by two graphite punches. The sintering temperature was increased from $600{ }^{\circ} \mathrm{C}$ to $1500{ }^{\circ} \mathrm{C}$ at the rate of $17{ }^{\circ} \mathrm{C}$ /min and held for $60 \mathrm{~min}$ while applying the pressure of $80 \mathrm{MPa}$. After the synthesis, wide surfaces of the ceramic sample were polished. In the course of study, the following measurements were carried out for all the prepared samples.

The in-line transmittance was evaluated by using JASCO V670 spectrometer in the spectral range from 190 to $2700 \mathrm{~nm}$ with $1 \mathrm{~nm}$ step. The PL emission spectrum and the PL decay lifetime monitoring at $410 \mathrm{~nm}$ were measured with $280 \mathrm{~nm}$ excitation using Hamamatsu Quantaurus- $\tau$ (C11367-04, Hamamatsu) and a short-cut filter (LU0300, Asahi Spectra). The $280 \mathrm{~nm}$ excitation is the shortest wavelength of LED equipped to Hamamatsu Quantaurus- $\tau$. In this condition, some leakage from the excitation source would affect the shorter wavelength ranges in the PL spectrum. The X-ray induced scintillation spectrum was measured using our lab-constructed setup. The sample was excited using an $\mathrm{X}$ ray generator in which the applied tube voltage and current were $40 \mathrm{kV}$ and $5.2 \mathrm{~mA}$, respectively. The scintillation emission was guided to either of the following two spectrometers: Andor CCD-based spectrometer (CCD, DU920-BU2NC, Andor; grating, SR163i-UV, Andor) or Ocean Photonics CCDbased spectrometer (QE65Pro). The details of the setup was described previously [30]. The former spectrometer was used for measuring a spectrum in the UV and visible range while the latter was used for the NIR wavelengths. Further, the X-ray induced afterglow was measured using an afterglow characterization system equipped with a pulsed X-ray tube [31], which was designed and constructed by us, and it became commercially available from Hamamatsu as a custom-ordered instrument. An afterglow level was calculated using the formula of one of the famous companies for scintillation detectors in security applications [32]. After samples were annealed at $1000{ }^{\circ} \mathrm{C}$ for 20 minutes, and then left in the dark for a while, the afterglow was measured. The afterglow is TSL around room temperature and has a significant relation with dosimeter properties.

In order to investigate the properties of $\mathrm{MgO}$ ceramic as a TSL dosimetric detector, we have measured 
a TSL glow curve using Nanogray TL-2000 [33] after X-ray irradiations with various doses from 0.1 mGy to $1000 \mathrm{mGy}$. The heating rate used for all the TSL measurements was fixed to $1{ }^{\circ} \mathrm{C} / \mathrm{s}$, and the sample was heated from 50 to $300{ }^{\circ} \mathrm{C}$ to measure the glow curve. Further, TSL spectrum was measured using an Andor CCD-based spectrometer as mentioned above while the sample was heated by an electric heater (SCR-SHQ-A, Sakaguchi E.H Voc) at a constant temperature.

\section{Results and discussion}

\section{1 Sample}

The synthesized $\mathrm{MgO}: \mathrm{Cr}^{3+}$ translucent ceramic samples are illustrated in Fig. 1. The top image shows the samples under room light while the bottom image shows those under UV (302 nm) light. As seen in the figure, these samples are visually transparent. It looks like that the PL emission becomes feeble with higher concentration of $\mathrm{Cr}$ added.

\section{2 Optical properties}

Fig. 2 shows the in-line transmittance spectra of $\mathrm{MgO}$ samples. For all the samples, at $220 \mathrm{~nm}$ and shorter wavelengths, the transmittance is close to zero. These wavelengths are longer than the wavelength of the bandgap of $\mathrm{MgO}(\sim 7.8 \mathrm{eV}=159 \mathrm{~nm})$ [6]. The $0.1 \% \mathrm{Cr}$-doped sample show absorption bands in the visible region. The mechanism responsible for these bands is explained in the literature in terms of crystal field splitting [34, 35]. The octahedral crystal field around the $\mathrm{Cr}^{3+}$ ion splits the ${ }^{4} \mathrm{~F}$ level into a ground state of singlet ${ }^{4} \mathrm{~A}_{2}$ and excited states of triplet ${ }^{4} \mathrm{~T}_{2}$ and ${ }^{4} \mathrm{~T}_{1}$. Also, due to the crystal field, splitting of the free-ion excited state of ${ }^{2} \mathrm{G}$ gives rise to level ${ }^{2} \mathrm{E}$. The broad absorption bands are due to transitions from ${ }^{4} \mathrm{~A}_{2}$ to the ${ }^{4} \mathrm{~T}_{2}$ (absorption around $665 \mathrm{~nm}$ ) and ${ }^{4} \mathrm{~T}_{1}$ (absorption around $455 \mathrm{~nm}$ ) levels.

Fig. 3 represents the PL spectra of the $\mathrm{MgO}$ ceramic doped with $\mathrm{Cr}^{3+}(0.001,0.01$ and $0.1 \%)$ samples under $280 \mathrm{~nm}$ excitation. The emission bands appeared around 350 and $410 \mathrm{~nm}$, and the former peak is due to the excitation leakage. Moreover, the broad and sharp emission peaks appeared around 600-850 $\mathrm{nm}$ in all the samples. Since emission wavelength agrees with that of trivalent $\mathrm{Cr}$ ion in $\mathrm{MgO}$ [36-39], this emission should be due to the electron transitions of $\mathrm{Cr}^{3+}$ ion. The sharp peaks around 600-850 nm mainly originates from ${ }^{2} \mathrm{E} \rightarrow{ }^{4} \mathrm{~A}_{2}$ transitions in $\mathrm{Cr}^{3+}$ ion placed at $\mathrm{Mg}^{2+}$ substitutional site with octahedral symmetry. Another broad peak around $600-850 \mathrm{~nm}$ is due to ${ }^{4} \mathrm{~T}_{2} \rightarrow{ }^{4} \mathrm{~A}_{2}$ transitions in $\mathrm{Cr}^{3+}$ ion if the ${ }^{4} \mathrm{~T}_{2}$ level shifts below the ${ }^{2} \mathrm{E}$ as expected for $\mathrm{Cr}^{3+}-\mathrm{Mg}$ vacancy pairs aligned with a $\mathrm{MgO}\left[\begin{array}{lll}1 & 1 & 0\end{array}\right]$ direction [36]. From 0.001 to $0.01 \%$, the peak intensity around $600-850 \mathrm{~nm}$ increased. However, from 0.01 to $0.1 \%$, the peak intensity around $600-850 \mathrm{~nm}$ decreased. The decrease of the peak intensity may be caused by the concentration quenching. The peak at $410 \mathrm{~nm}$ is attributed to oxygen vacancies with one electrons $\left(\mathrm{F}^{+}\right.$ center) which was observed in the undoped $\mathrm{MgO}[18,27]$.

The PL decay time constants of the $\mathrm{MgO}: \mathrm{Cr}^{3+}$ translucent ceramics are shown in Fig. 4. The inset shows the measured PL decay curves. Here, the excitation wavelength is $280 \mathrm{~nm}$ and the monitoring 
emission wavelength is $750 \mathrm{~nm}$. The decay curves of all the samples are well approximated by a sum of two exponential functions. The obtained faster decay time components of $0.001,0.01$ and $0.1 \% \mathrm{Cr}$-doped samples resulted 870, 355 and $228 \mu$ s, respectively. Possibly, the obtained faster components would be ascribed to ${ }^{4} \mathrm{~T}_{2} \rightarrow{ }^{4} \mathrm{~A}_{2}$ transitions of $\mathrm{Cr}^{3+}$ ion, and the excitation pulse may also affect. The obtained slower decay time components of 0.001, 0.01 and $0.1 \%$ Cr-doped samples resulted 3.78, 2.02 and $0.95 \mathrm{~ms}$, respectively. These slower components are due to $\mathrm{Cr}^{3+}$ emission because the observed values are consistent with typical decay times of ${ }^{2} \mathrm{E} \rightarrow{ }^{4} \mathrm{~A}_{2}$ transitions [40, 41], and shortening of decay time with $\mathrm{Cr}^{3+}$ concentration would be due to concentration quenching.

\section{3 Scintillation properties}

Fig. 5 shows the scintillation spectra of $\mathrm{MgO}$ translucent ceramic samples doped with $\mathrm{Cr}^{3+}(0.001,0.01$ and $0.1 \%$ ). All the samples showed an emission peak around 600-850 nm due to $\mathrm{Cr}^{3+}$. The emission intensity showed a similar behavior of PL spectra against the $\mathrm{Cr}$ concentration. Unlike PL, no $\mathrm{F}^{+}$center emission around $410 \mathrm{~nm}$ was detected or it was embedded in the tail part of the $350 \mathrm{~nm}$ emission. Although the origin of the $350 \mathrm{~nm}$ emission is still unclear because it was not detected in typical PL studies, this peak was only observed in OSL spectrum [42]. We think that the origin would relate to surface (grain boundary) defects [43], but further investigation will be required.

In Fig. 6, the afterglow levels are shown. The inset shows the afterglow profiles. The obtained afterglow levels of $0.001,0.01$ and $0.1 \% \mathrm{Cr}$-doped samples are $0.17,0.12$ and $0.11 \%$, respectively. The afterglow levels were in inverse proportion to the $\mathrm{Cr}$ concentration.

\section{4 Dosimeter properties}

Fig. 7 shows TSL glow curves measured after the samples were irradiated with an X-ray dose of $1 \mathrm{~Gy}$. All the samples showed glow peaks around 85 and $140{ }^{\circ} \mathrm{C}$. These peaks are typical in $\mathrm{MgO}$ and is consistent with the previous works reported in the literatures [8-12]. In addition, the more amount of dopant added, the lesser TSL intensity, and the TSL peak temperature slightly shifted to lower temperature. These results were consistent with afterglow results that afterglow level was intense in lower $\mathrm{Cr}$ concentration. The activation energy and the frequency factor were derived using the initial rise method [44] on the assumption of first order kinetic [45], and the estimated value was summarized in Table 1. As Cr concentration increase, the activation energy was lower, in comparison with that of undoped $\mathrm{MgO}$ in Ref [8] which was evaluated with the same manner. This fact indicates that the trap depth shallowed by $\mathrm{Cr}$-doping. Additionally, the frequency factor values were in inverse proportion to the $\mathrm{Cr}$ concentration, and it showed that Cr-doping suppressed the thermal ionization probability from $\mathrm{F}$ centers in $\mathrm{MgO}$. From this analysis, if more pure $\mathrm{MgO}$ powder which is not contaminated with $\mathrm{Cr}$ is available, the TSL properties of $\mathrm{MgO}$ would be improved.

Fig. 8 depicts the TSL spectra around $140{ }^{\circ} \mathrm{C}$. The emission bands were detected around 340 and 600 - 
$850 \mathrm{~nm}$. The TSL peak at $140{ }^{\circ} \mathrm{C}$ was by the $\mathrm{F}^{+}$center and $\mathrm{Cr}^{3+}$ ion. However, it should be noted that emission from the 600-850 $\mathrm{nm}$ bands was not accumulated in TSL glow curves (Fig. 7) since the thermal radiation cut filter had a transmittance up to $520 \mathrm{~nm}$ was equipped in the instrument. As a result, $\mathrm{F}^{+}$center and $\mathrm{Cr}^{3+}$ emissions had a same dopant concentration dependence (Fig. 8), and whether $\mathrm{Cr}^{3+}$ emission was included in TSL glow curves or not did not affect the discussion.

Fig. 9 shows the relation between the TSL intensity and irradiated X-ray dose, namely the dose response curve. By using the dose response curve, we can calibrate the TSL response to the corresponding dose value in practical uses. The TSL signal used here is the integrated peak intensity at $140{ }^{\circ} \mathrm{C}$ in Fig. 7. From our experimental results, the $0.001,0.01$ and $0.1 \% \mathrm{Cr}$-doped $\mathrm{MgO}$ transparent ceramics have a linear response against the incident X-ray dose over the dose range of 0.1-1000 mGy. The linear response was confirmed the tested range and calculated coefficient of determinations of $0.001,0.01$ and $0.1 \% \mathrm{Cr}$ doped $\mathrm{MgO}$ are $0.9759,0.9815$ and 0.9649 , respectively. It is an equivalent sensitivity with commercial personal dosimeters and the highest sensitivity for $\mathrm{MgO}$ among the earlier reported works we could find [46-48]. Dosimeter having a linear response is advantageous because it enables us to easily and accurately calibrate the dose.

\section{Conclusions}

We have synthesized $\mathrm{MgO}$ translucent ceramics doped with $\mathrm{Cr}^{3+}$ ion by an SPS technique. All the samples were visually transparent. Subsequently, we have studied the optical, scintillation and TSL properties. In the PL and scintillation emissions, the optimum $\mathrm{Cr}^{3+}$ concentration turned out to be around $0.01 \%$. The TSL glow curves of all the samples had the main peak around $140{ }^{\circ} \mathrm{C}$. Using this glow peak, the $\mathrm{MgO}: \mathrm{Cr}^{3+}$ samples had a dose detection ability at least over the range 0.1-1000 mGy Furthermore, the dose response was linear over the dose range tested. Among the present samples, lower $\mathrm{Cr}$ concentration was preferable for TSL dosimeter.

\section{Acknowledgements}

This work was supported by a Grant-in-Aid for Scientific Research (A) 26249147 from the Ministry of Education, Culture, Sports, Science and Technology of Japan (MEXT) and partially by JST Astep. Green Photonics Research from MEXT and the Cooperative Research Project of Research Institute of Electronics, Shizuoka University, are also acknowledged.

\section{References}

[1] T. Yanagida, A. Yoshikawa, Y. Yokota, K. Kamada, Y. Usuki, S. Yamamoto, M. Miyake, M. Baba, K. Sasaki and M. Ito, IEEE Trans. Nucl. Sci., 571492 (2010).

[2] D. Totsuka, T. Yanagida, K. Fukuda, N. Kawaguchi, Y. Fujimoto, Y. Yokota and A. Yoshikawa, Nucl. Instrum. Methods A., 659399 (2011).

[3] M. R. Mayhugh, R. W. Chrisy and N. M. Johnson, J. Appl. Phys., 412968 (1970).

[4] S.W.S. McKeever, Radiat. Meas., 461336 (2011).

[5] Y. Miyamoto, Y. Takei, H. Nanto, T. Kurobori, A. Konnai, T. Yanagida, A. Yoshikawa, Y. 
Shimotsuma, M. Sakakura, K. Miura, K. Hirao, Y. Nagashima and T. Yamamoto, Radiat. Meas., 46 1480 (2011).

[6] D.M. Roessler and W.C. Walker, Phys. Rev., 159733 (1967).

[7] C. Klein and C.S. Hurlbut Jr., Manual of Mineralogy, John Wiley \& Sons, New York, 1999.

[8] H. Nanto, K. Inabe, H. Yamazaki and N. Takeuchi, J. Phys. Chem. Solid., 36477 (1975).

[9] N. Takeuchi, K. Inabe and H. Nanto, Solid. State. Commun., 171267 (1975).

[10] W.A. Sibley, J.L. Kolopus and W.C. Mallard, Phys. Status Solidi., 31223 (1969).

[11] A. Sathyamoorthy and J.M. Luthra, J. Mater. Sci., 132637 (1978).

[12] S. A. Dolgov, V. Isakhanyan, T. Kärner, P. Liblik, A. Maaroos and S. Nakonechnyi, Radiat. Meas., 38699 (2004).

[13] T. Uchino, D. Okutsu, R. Katayama and S. Sawai, Phys. Rev. B., 79165107 (2009)

[14] H. Soma, Y. Uenaka, A. Asahara, T. Suemoto and T. Uchino, Appl. Phys. Lett., 106041116 (2015).

[15] Y. Yanagisawa and R. Huzimura, J. Phys. Soc. Jpn., 5366 (1984).

[16] G.P. Summers, T.M. Wilson, B.T. Jeffries, H.T. Tohver, Y. Chen and M.M. Abraham, Phys. Rev. B., 271283 (1983).

[17] C. Martinez-Boubeta, A. Martinez, S. Hernandez, P. Pellegrino, A. Antony, J. Bertomeu, Ll. Balcells, Z. Konstantinovic and B. Martinez, Solid. State. Commun., 151751 (2011).

[18] G.H. Rosenblatt, M.W. Rowe, G.P. Williams Jr., R.T. Williams and Y. Chen, Phys. Rev. B., 39 10309 (1989).

[19] Y. Chen, J.L. Kolopus and W.A. Sibley, Phys. Rev. B., 186865 (1969).

[20] L.A. Kappers, R.L. Kroes and E.B. Hensley, Phys. Rev. B 1(10-15), 4151-4157 (1970).

[21] T. Jeffries, R. Gonzalez, Y. Chen and G.P. Summers, Phys. Rev. B 25(3), 2077-2080 (1982).

[22] Y. Uenaka and T. Uchino, Phys. Rev. B., 83195108 (2011).

[23] Y. Fang, D. Agrawal, G. Skandan and M. Jain, Mater. Lett., 58551 (2004).

[24] R. Chaim, Z. Shen and M. Nygren, J. Mater. Res., 192527 (2004).

[25] D. Chen, E.H. Jordan and M. Gell, Scripta. Mater., 59757 (2008)

[26] R. Chaim, R. Marder and C. Estourns, Scripta. Mater., 63211 (2010).

[27] S. Wakahara, T. Yanagida, Y. Yokota, Y. Fujimoto, V. Chani, M. Sugiyama, Y. Futami and A. Yoshikawa, Opt. Mater., 35558 (2013).

[28] T. Yanagida, Y. Fujimoto, K. Watanabe, K. Fukuda, N. Kawaguchi, Y. Miyamoto and H. Nanto, Radiat. Meas., 71162 (2014).

[29] T. Yanagida, J. Lumin., doi:10.1016/j.jlumin.2015. 01.006 in press (2015).

[30] T. Yanagida, K. Kamada, Y. Fujimoto, H. Yagi and T. Yanagitani, Opt. Mater., 352480 (2013).

[31] T. Yanagida, Y. Fujimoto, T. Ito, K. Uchiyama and K. Mori, Appl. Phys. Exp., 7062401 (2014).

[32] http://www.nk-k.co.jp/products/Detector_j.html

[33] T. Yanagida, Y. Fujimoto, N. Kawaguchi, S. Yanagida and J. Ceram. Soc. Jpn., 121988 (2013).

[34] J.F.H. Nicholls, T.P.J. Han, B. Henderson, F. Jaque, Chem. Phys. Lett., 202560 (1993).

[35] R. Bhatt, S. Kar, K.S. Bartwal, V.K. Wadhawan, Solid. State. Commun., 127457 (2003).

[36] M. O. Henry, J. P. Larkin and G. F. Imbusch, Phys. Rev. B., 131893 (1976)

[37] F. Stavale, N. Nilius and H. Freund, New. J. Phys., 14 (2012)

[38] S. Karaveil, S. Wang, G. Xiao and R. Zia, Acs. Nano., 77165 (2013)

[39] I. S. Altman, P. V. Pikhitsa, M. Choi and J. I. Jeong, Appl. Phys. Lett., 833689 (2003)

[40] Z. Pan, Y. Lu and F. Liu, Nat. Mater., 11, 58 (2012)

[41] J. S. Kim, J. S. Kim and H. L. Park, Solid. State. Commun., 131735 (2004)

[42] L. C. Oliveira, B. A. Doull, E. G. Yukihara, J. Lumin., 137282 (2013)

[43] F. Gu, C. Li, H. Cao, W. Shao, Y. Hu, J. Chen, A. Chen, J. Alloy. Compd., 453361 (2008)

[44] S. W. S Mckeever. Thermoluminescence of solid, Cambridge University Press, New York, 1985.

[45] M. Fasoli, A.Vedda, F. Moretti, A. C. Chenus, I. Veronese, M. C. Cantone, M. Nikl, A. Yoshikawa, A. Novoselov, Radiat. Meas., 45556 (2010)

[46] V. Kvatchadze, G. Dekanozishvili, M. Galustashvili, T. Kalabegishvili, N. Keratishvili and D. Zaradiashvili, Phys. Stat. Sol., 2043174 (2007)

[47] A. J. J. Bos, M. prokic and J. C. Brouwer, Radiat. Prot. Dosim., 119130 (2006).

[48] C. Soliman, Radiat. Eff. Defect. S., 164257 (2009). 
Fig. $1 \mathrm{MgO}$ ceramic doped with $\mathrm{Cr}^{3+}(0.001,0.01$ and $0.1 \%)$ samples under room light (top) and UV (302 nm) light (bottom).

Fig. 2 Transmittance of $\mathrm{MgO}$ transparent ceramic samples doped with $\mathrm{Cr}^{3+}(0.001,0.01$ and $0.1 \%)$.

Fig. 3 PL emission spectra of the $\mathrm{MgO}$ transparent ceramic samples doped with $\mathrm{Cr}^{3+}(0.001,0.01$ and $0.1 \%$ ) under $280 \mathrm{~nm}$ excitation.

Fig. 4 PL decay times of the $\mathrm{MgO}$ transparent ceramic samples doped with $\mathrm{Cr}^{3+}(0.001,0.01$ and $0.1 \%)$. The monitoring PL emission wavelength is $750 \mathrm{~nm}$ during the excitation at $280 \mathrm{~nm}$. The inset shows the PL decay profiles.

Fig. $5 \mathrm{X}$-ray induced scintillation spectra of the $\mathrm{MgO}$ transparent ceramics doped with $\mathrm{Cr}^{3+}(0.001,0.01$ and $0.1 \%)$. The inset expands the 300-700 nm wavelength region.

Fig. 6 Afterglow levels of $\mathrm{MgO}$ transparent ceramics doped with $\mathrm{Cr}^{3+}(0.001,0.01$ and $0.1 \%)$. The inset shows the afterglow profiles.

Fig. 7 TSL glow curves of $\mathrm{MgO}$ transparent ceramics doped with $\mathrm{Cr}^{3+}(0.001,0.01$ and $0.1 \%)$ samples. The inset expands from 0 to 0.4 TSL intensity for $\mathrm{Cr}^{3+} 0.1 \%$ sample.

Fig. $8 \mathrm{TSL}$ spectra measured at $140{ }^{\circ} \mathrm{C}$ for the $\mathrm{MgO}$ transparent ceramic samples doped with $\mathrm{Cr}^{3+}(0.001$, 0.01 and $0.1 \%$ ). The inset expands 300-700 nm wavelength regions.

Fig. 9 Dose response curves of the $\mathrm{MgO}$ transparent ceramic samples doped with $\mathrm{Cr}^{3+}(0.001,0.01$ and $0.1 \%)$. The TSL signal used here is the peak intensity observed at $140{ }^{\circ} \mathrm{C}$.

Table. 1 The activation energy and the frequency factor of the nondoped and $\mathrm{Cr}$-doped $\mathrm{MgO}$. 


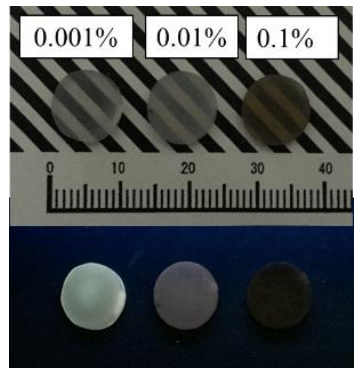

Fig. $1 \mathrm{MgO}$ ceramic doped with $\mathrm{Cr}^{3+}(0.001,0.01$ and $0.1 \%)$ samples under room light (top) and UV (302 nm) light (bottom). 


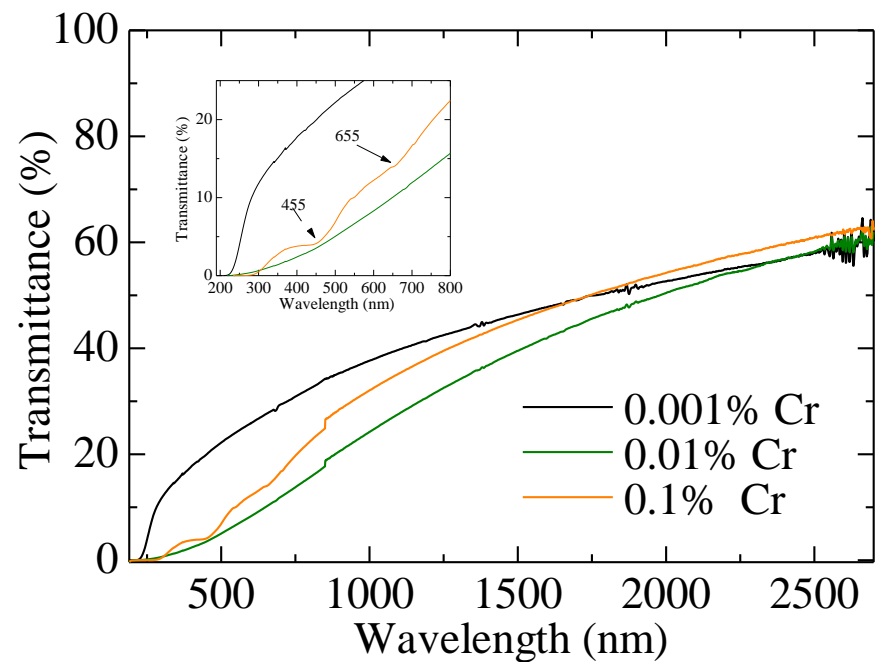

Fig. 2 Transmittance of $\mathrm{MgO}$ transparent ceramic samples doped with $\mathrm{Cr}^{3+}(0.001,0.01$ and $0.1 \%)$. 


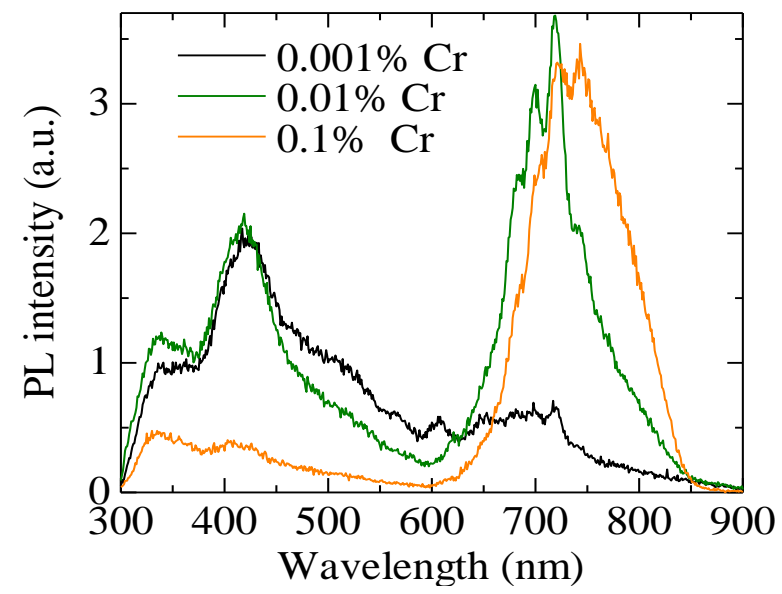

Fig. 3 PL emission spectra of the $\mathrm{MgO}$ transparent ceramic samples doped with $\mathrm{Cr}^{3+}(0.001,0.01$ and $0.1 \%$ ) under $280 \mathrm{~nm}$ excitation. 


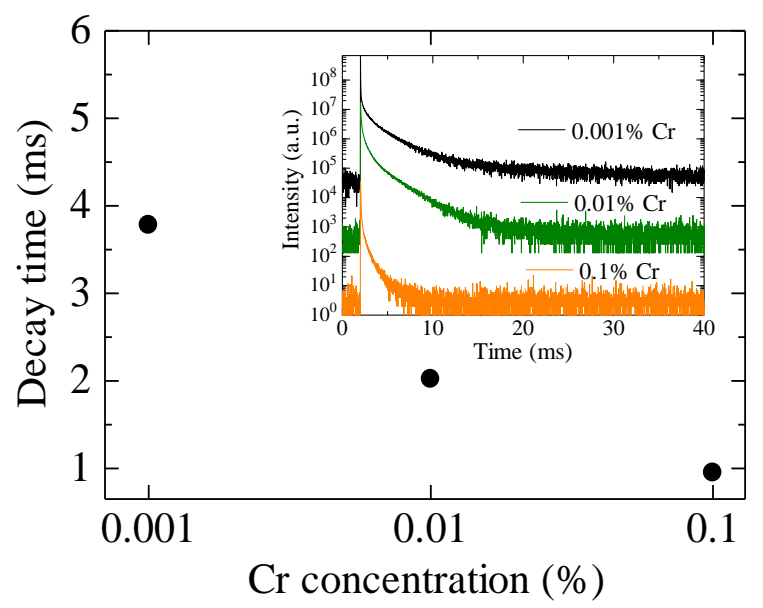

Fig. 4 PL decay times of the $\mathrm{MgO}$ transparent ceramic samples doped with $\mathrm{Cr}^{3+}(0.001,0.01$ and $0.1 \%)$. The monitoring PL emission wavelength is $750 \mathrm{~nm}$ during the excitation at $280 \mathrm{~nm}$. The inset shows the PL decay profiles. 


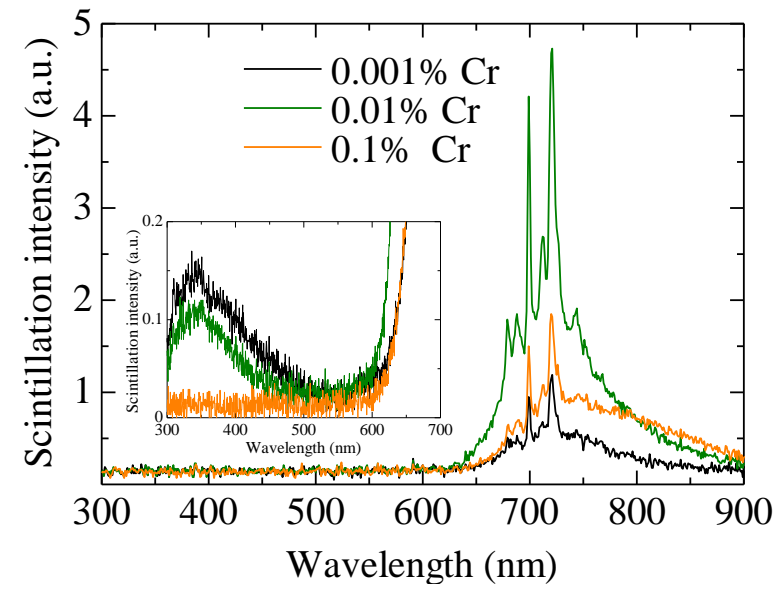

Fig. 5 X-ray induced scintillation spectra of the $\mathrm{MgO}$ transparent ceramics doped with $\mathrm{Cr}^{3+}(0.001,0.01$ and $0.1 \%$ ). The inset expands the 300-700 $\mathrm{nm}$ wavelength region. 


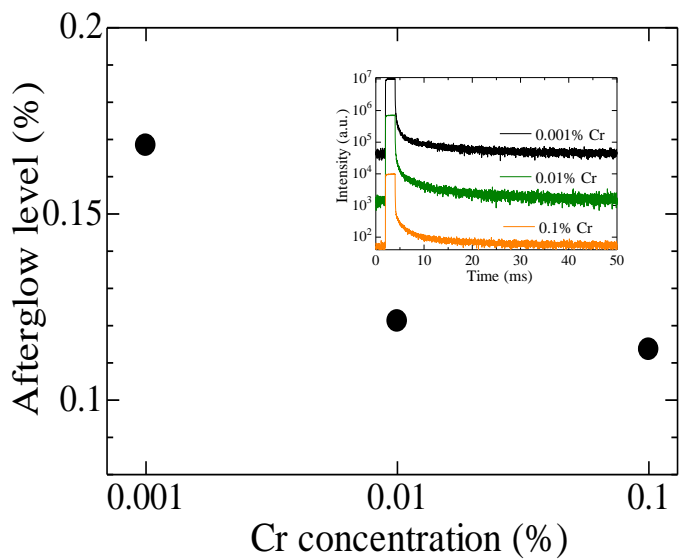

Fig. 6 Afterglow levels of $\mathrm{MgO}$ transparent ceramics doped with $\mathrm{Cr}^{3+}(0.001,0.01$ and $0.1 \%)$. The inset shows the afterglow profiles. 


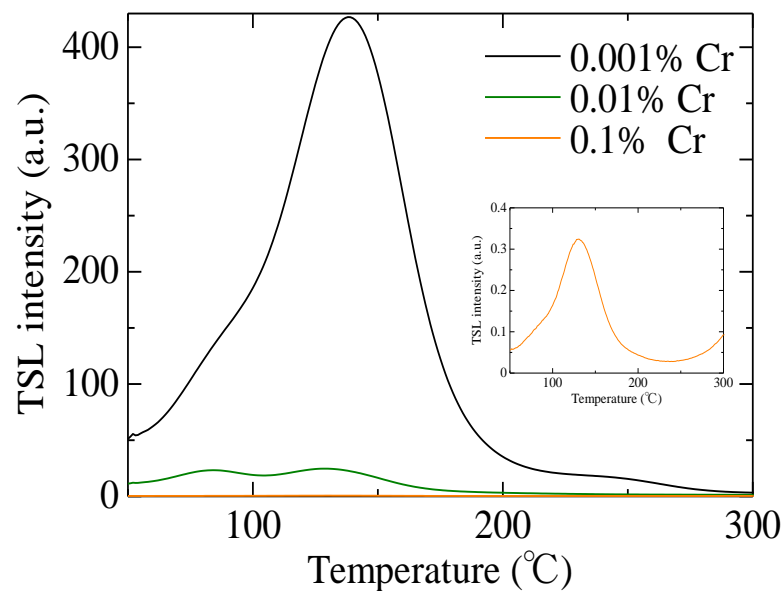

Fig. 7 TSL glow curves of $\mathrm{MgO}$ transparent ceramics doped with $\mathrm{Cr}^{3+}(0.001,0.01$ and $0.1 \%)$ samples. The inset expands from 0 to 0.4 TSL intensity for $\mathrm{Cr}^{3+} 0.1 \%$ sample. 


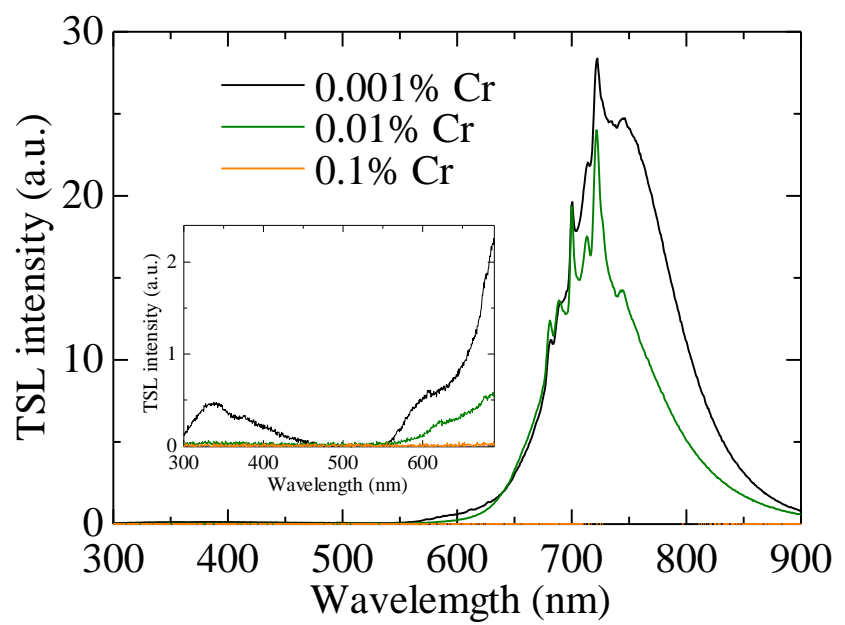

Fig. 8 TSL spectra measured at $140{ }^{\circ} \mathrm{C}$ for the $\mathrm{MgO}$ transparent ceramic samples doped with $\mathrm{Cr}^{3+}(0.001$, 0.01 and $0.1 \%)$. The inset expands 300-700 nm wavelength regions. 


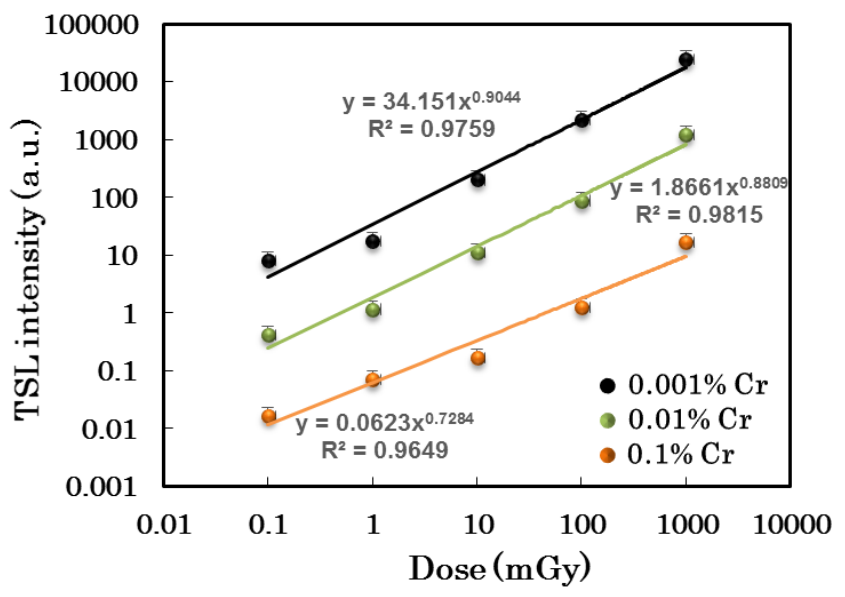

Fig. 9 Dose response curves of the $\mathrm{MgO}$ transparent ceramic samples doped with $\mathrm{Cr}^{3+}(0.001,0.01$ and $0.1 \%)$. The TSL signal used here is the peak intensity observed at $140{ }^{\circ} \mathrm{C}$. 


\begin{tabular}{cccc}
\hline Samples & $\begin{array}{c}\text { Peak } \\
\text { Temperature } \\
\left({ }^{\circ} \mathrm{C}\right)\end{array}$ & $\begin{array}{c}\text { Activation } \\
\text { energy } \\
(\mathrm{eV})\end{array}$ & $\begin{array}{c}\text { Frequency } \\
\text { factor } \\
\left(\mathrm{s}^{-1}\right)\end{array}$ \\
\hline Ref $[8]$ & 144 & 1.03 & - \\
$0.001 \% \mathrm{Cr}$ & 139 & 0.29 & $8.02 \times 10^{9}$ \\
$0.01 \% \mathrm{Cr}$ & 130 & 0.21 & $2.43 \times 10^{7}$ \\
$0.1 \% \mathrm{Cr}$ & 130 & 0.15 & $1.62 \times 10^{4}$ \\
\hline
\end{tabular}

Table. 1 The activation energy and the frequency factor of the nondoped and $\mathrm{Cr}$-doped $\mathrm{MgO}$. 